\title{
Theodor M Fliedner (1 October 1929-9 November 2015), transplant pioneer
}

Bone Marrow Transplantation (2016) 51, 471-472; doi:10.1038/ bmt.2016.1

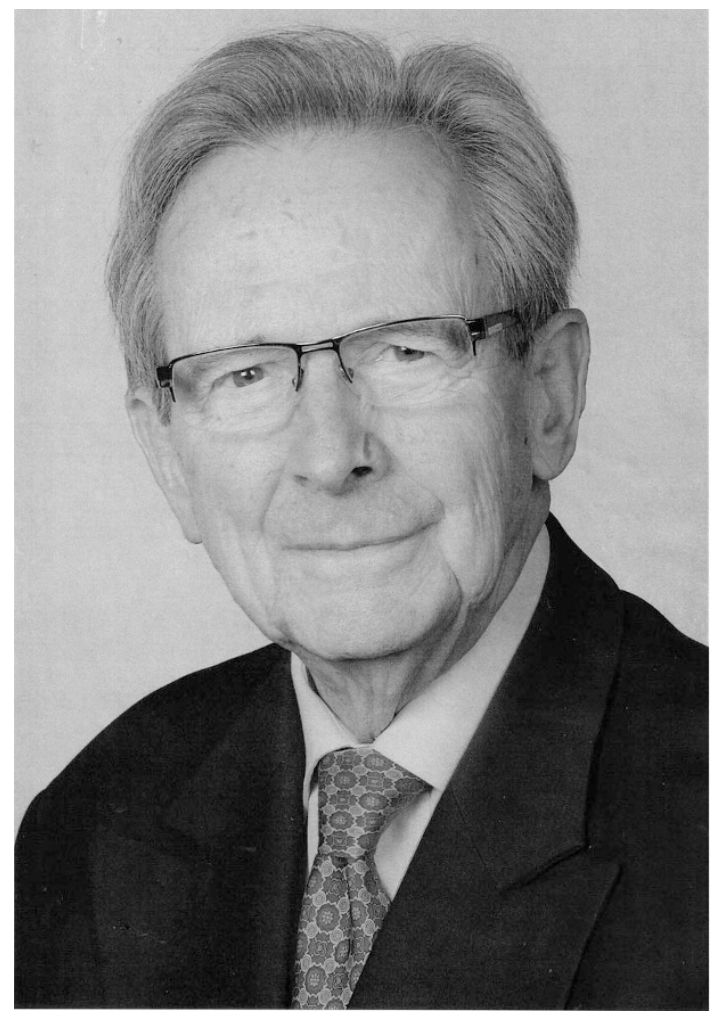

Professor Theodor M Fliedner died in Ulm, Germany on 9 November 2015. Ted was a transplant pioneer whose main research interests were radiation biology and haematopoietic stem cells. The atomic bombings in Japan in 1945 created a huge interest in the United States and Europe in radiation protection: how to save troops and civilians from the potentially devastating effects of a nuclear weapon. Fliedner began his research early with his doctoral dissertation: 'On the pathogenesis of acute bone marrow atrophy in rats after whole-body irradiation with fast electrons'. In 1955, he established a radiation haematology research unit in the basement of Czerny-Hospital in Heidelberg (concrete walls provide reasonably good shielding). In 1957, Ted went to the Brookhaven National Laboratory to study with Eugene P Cronkite. At that time the existence of haematopoietic stem cells was postulated but they were unproved and unidentified. It is worth recalling that at that time survival of mice receiving wholebody radiation with spleen shielding was thought by some to result from the effects of factors released from the spleen on residual bone marrow cells and not on protected spleen haematopoietic stem cells. (Interestingly, this misunderstanding led to the discovery of erythropoietin.) However, Fliedner was on the right track. He gave dogs high doses of nitrogen mustard followed by a bone marrow transplant and was able to show that a large proportion of haematopoietic stem cells were nondividing. Later, he and his colleagues developed techniques to collect and freeze bone marrow cells from dogs and humans, techniques that were later used for autotransplants in individuals with solid cancers following high doses of nitrogen mustard. This strategy, developed in the late 1980s, should sound familiar to haematologists today doing autotransplants for lymphomas and plasma cell myeloma.

In 1963, Professor Fliedner returned to Europe to direct the EURATOM Institute for Radiation Haematology Research in Freiburg. He and his team studied the behaviour of resting haematopoietic stem cells in rats by infusing tritiated thymidine $\left({ }^{3} \mathrm{H}\right.$-thymidine). Using this technique, they determined the cell cycle state of normal and leukaemic haematopoietic stem cells and defined the kinetics of normal and neoplastic myelopoiesis. Much of the current knowledge of RBC and granulocyte production rates, proliferative rates and lifespans of leukaemia cells comes from these studies. The team also postulated the existence of a stem cell niche years ahead of others based on the experimental data from auto-radiographs of ${ }^{3} \mathrm{H}$-thymidinelabelled human bone marrow biopsies.

Fliedner realized infections would be a problem in successfully treating radiation accident victims, those with leukaemia with drug-induced bone marrow failure and transplant recipients. In 1969, after returning to Ulm, he and his team developed a germfree tent now called a Life-Island. Soon thereafter twins with SCID arrived at the hospital. Their five siblings had died early of infection. The team kept them in an isolation tent for 2 years until they received a parental bone marrow transplant. Both survive today.

In 1967, Ted became director of the Department of Clinical Physiology and later dean of the Theoretical Faculty of Medicine. His research focused on characterizing haematopoiesis in dogs after exposure to total body radiation. Fliedner was concerned about treating radiation accident victims and chaired a European consortium of experts who developed the 1981 publication Manual on the Acute Radiation Syndrome, widely used today. In it he described the METREPOL (MEdical TREatment ProtocOLs for radiation accident victims) system for classifying injuries, estimating radiation dose after accidental exposures and selecting appropriate interventions. He also established a database of radiation accidents with over 800 detailed reports. Even after retirement and at age 82 years, he asked one of us (RPG) to send him slides from a victim of a radiation accident in Israel to review for his registry.

In 1974, Professor Fliedner was appointed a director general of the World Health Organization (WHO) and in 1983-87 chaired the WHO European Advisory Committee on Health Research. In 1983, he was also appointed President of the University of Ulm. Ted Fliedner received many honours and was a member or honourary member of many medical academies and scientific bodies, and received numerous awards.

Ted Fliedner was a man of vision highly respected in the international scientific community. He loved research and especially favoured open, critical discussions. Everyone who worked with him or knew him returns to a few descriptors, charisma and passion. He 
was inspired and inspired others to do their best work. Co-workers describe lab experiments and discussions lasting until 2 in the morning. No one ever complained (or did so openly). We suspect, however, that there were many disgruntled wives. His personality likely reflected his missionary evangelical family history. Ted was a true scientist, but we can never escape our genes. Ted is survived by his wife, five children and six grandchildren. Perhaps one of them will become a great scientist.
The bone marrow transplant community has lost one of its founders. He will be greatly missed.

D Hoelzer ${ }^{1}$ and RP Gale ${ }^{2}$ ${ }^{1}$ University Hospital, Frankfurt, Germany and ${ }^{2}$ Imperial College, London, London, UK E-mail: dieter.hoelzer@onkologikum-frankfurt.de 